\title{
Produção de Lipases por Fermentação no Estado Sólido
}

\author{
L. M. PINOTTI ${ }^{1}$, J. X. LACERDA ${ }^{1,}$ M. M. OLIVEIRA e R. D. TEIXEIRA ${ }^{1}$ \\ ${ }^{1}$ Universidade Federal do Espírito Santo, Departamento de Engenharias e Tecnologia \\ E-mail para contato: pinotti2008@hotmail.com
}

\begin{abstract}
RESUMO - O interesse na produção de lipases está relacionado ao seu potencial tecnológico em reações de esterificação e transesterificação. No entanto, os processos de produção e recuperação das enzimas possuem custos elevados, inviabilizando muitas vezes a sua utilização. Neste contexto a fermentação em estado sólido surge como alternativa para redução dos custos, uma vez que permite o uso de resíduos agroindustriais de baixo valor agregado e propicia a produção do biocatalisador mais concentrado. Dessa forma, neste trabalho, tem-se como objetivo estudar a produção de lipases utilizando o bagaço de cana como substrato. Os microrganismos utilizados foram o Penicillium sp. e o Bacillus megaterium e as condições operacionais estudadas foram temperatura $\left(28,33\right.$ e $\left.38^{\circ} \mathrm{C}\right)$, teor de umidade $(40,50$ e $60 \%)$ e concentração do indutor óleo de oliva (1, 3 e 5\%), através de um planejamento fatorial $\left(3^{3}\right)$. O microrganismo melhor produtor de lipases foi o Penicillium $s p .(0,3$ $\mathrm{UI} / \mathrm{g}_{\text {substrato }}$ ), embora ainda muito baixo e com uma diferença muito pouco significativa quando comparada com a do B. megaterium $\left(0,2 \mathrm{UI} / \mathrm{g}_{\text {substrato }}\right)$. O teor de umidade do meio de cultivo interferiu na produção enzimática para ambos os microrganismos.
\end{abstract}

\section{INTRODUÇÃO}

A utilização de enzimas como biocatalisadores em processos industriais tem sido amplamente estudada e vem apresentando panorama promissor para produção de compostos de alto valor agregado. Segundo Vargas (2004), são conhecidas atualmente cerca de 4.000 enzimas e destas, em torno de 200 são aplicadas em processos comerciais. Dentre as enzimas utilizadas como biocatalisadores destacam-se as lipases (E.C.3.1.1.3), que catalisam a quebra de gorduras e óleos liberando ácidos graxos, diacilgliceróis, monoacilgliceróis e glicerol, podendo também catalisar reações de esterificação, transesterificação e interesterificação quando a quantidade de água do sistema em que estão presentes é suficientemente baixa a ponto de deslocar o equilíbrio termodinâmico no sentido de síntese. Essas enzimas apresentam uma ampla gama de substratos, possuem estabilidade à mudanças de temperatura e $\mathrm{pH}$ e à concentrações diferentes de solventes orgânicos e ainda catalisam reações apresentando alta quimio-regio e enantiosseletividade (Hasan et al., 2006, Krieger et al., 2004, Pastore et al., 2003).

As lipases são comumente encontradas na natureza, podendo ser obtidas a partir de fontes animais (lipases pancreáticas, hepáticas e gástricas), vegetais e microbianas. Tanto microrganismos 


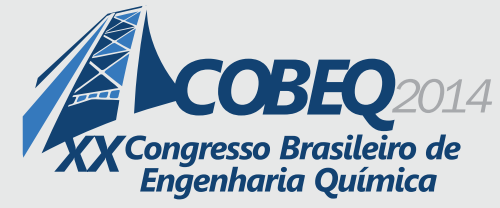

19 a 22 de outubro de 2014

Florianópolis/SC

eucariotos (leveduras e fungos) como procariotos (bactérias, incluindo-se os actinomicetos), são produtores de lipases e suas propriedades variam de acordo com a procedência. As enzimas microbianas são mais frequentemente utilizadas devido à grande variedade de atividade catalítica, à facilidade de manipulação genética, rápido crescimento, são mais estáveis e a sua produção é mais conveniente e mais segura (Menoncin, 2007). Microrganismos de uma mesma linhagem possuem o potencial de produzir enzimas com características completamente ou parcialmente diferenciadas, e por esse motivo a busca por novas fontes microbianas continua sendo foco de vários pesquisadores (Messias et al., 2011).

Uma ferramenta de potencial interesse na obtenção de enzimas é a Fermentação em Estado Sólido (FES), pois permite o uso de rejeitos de outros processos industriais como substrato e suporte para o crescimento de microrganismos, reduzindo dessa forma o custo de produção das enzimas (Silva et al., 2002, Menoncin et al, 2009, Vargas, 2004). A FES tem como base o crescimento de microrganismos em substratos sólidos com baixa atividade de água e apresenta diversas vantagens quando comparada com a fermentação submersa tais como economia de espaço, simplicidade nos meios de fermentação, equipamentos simples e de fácil controle, altos rendimentos de produção, menor demanda energética, além de se obter o metabólito de interesse em uma concentração mais elevada. A absorção de água é essencial para o sucesso deste processo e, por este motivo são empregados substratos fibrosos, podendo estes fornecer os nutrientes necessários para o crescimento celular. Diversos resíduos agroindustriais podem ser empregados como suporte para a FES, como exemplos o bagaço de cana-de-açúcar e a casca de arroz (Oliveira et al., 2012).

Embora a FES apresente as vantagens acima descritas, têm-se algumas limitações tais como a escolha dos microrganismos capazes de crescer sob condições de umidade reduzida, controle e monitoramento de parâmetros tais como $\mathrm{pH}$, temperatura, umidade e fluxo de ar. Dentro deste cenário, o objetivo deste trabalho foi avaliar a produção de lipases por fermentação em estado sólido utilizando Penicillium sp. e B. megaterium, e bagaço de cana-de-açúcar como suporte e fonte de nutrientes. Investigou-se o efeito da temperatura, umidade e concentração do indutor óleo de oliva através da técnica de planejamento fatorial de experimentos $\left(3^{3}\right)$.

\section{METODOLOGIA}

\subsection{Microrganismos}

O B. megaterium foi cedido gentilmente pelo grupo de pesquisa do DEQ da UFSCar e mantido em ágar-slant (meio Luria-Bertani) e congelado em solução de glicerol $20 \%$. O Penicillium sp. foi isolado e cedido pelo grupo de pesquisa LABSAN/DEA/UFES e também mantido em ágar-slant (meio de ágar batata dextrose) e congelado em solução de glicerol $20 \%\left(-80^{\circ} \mathrm{C}\right)$. 


\subsection{Obtenção do Inóculo}

B. megaterium: A bactéria foi cultivada em meio Luria-Bertani (LB) em câmara rotativa a $37^{\circ} \mathrm{C}$. O tempo de obtenção do inóculo foi estudado e para isso foram retiradas amostras em intervalos de tempo e analisado a concentração celular por massa seca.

Penicillium sp.: O cultivo do fungo foi realizado em meio de PDA $3,9 \%$ à $28^{\circ} \mathrm{C}$. O tempo de obtenção de inóculo foi estudado e para isso foram retiradas amostras a cada 24 horas e analisado a concentração de esporos. Para isso os esporos foram raspados com $10 \mathrm{~mL}$ de twen80 $(0,1 \% \mathrm{v} / \mathrm{v})$ e contados em câmara de Neubauer.

\subsection{Produção Enzimática}

Para a produção da enzima foi utilizado bagaço de cana moído e peneirado até granulometria entre 0,6 e $1,18 \mathrm{~mm}$ de diâmetro. Esse substrato foi seco em estufa a $55^{\circ} \mathrm{C}$ por 24 horas. $\mathrm{O}$ bagaço de cana foi então adicionado em erlenmeyers e umedecido com tampão fosfato $0,1 \mathrm{~mol} / \mathrm{L} \mathrm{pH} \mathrm{7,0} \mathrm{para}$ obter a umidade desejada. Os frascos foram autoclavados a $121^{\circ} \mathrm{C}$ por 20 minutos e, após resfriamento, inoculados com $1 \mathrm{~mL}$ de inóculo líquido com concentração igual a $10^{8}$ esporos $/ \mathrm{mL}$. Foram estudados a temperatura de cultivo $\left(28,33\right.$ e $\left.38^{\circ} \mathrm{C}\right)$, o teor de umidade $(40,50$ e $60 \%)$ e a concentração do indutor óleo de oliva (1, 3 e 5\%) para o tempo de cultivo de 120 horas para o Penicillium sp. e 48 horas para o B. megaterium. Para a realização dos experimentos foi utilizado um planejamento fatorial do tipo $3^{3}$ (Tabela 1), com três pontos centrais, totalizando 29 experimentos para cada microrganismo.

Tabela 1 - Variáveis e níveis utilizados nos experimentos

\begin{tabular}{cccc}
\hline & -1 & 0 & +1 \\
\hline Temperatura de cultivo & 28 & 33 & 38 \\
Teor de umidade & 40 & 50 & 60 \\
$\begin{array}{c}\text { Concentração do } \\
\text { inductor }\end{array}$ & 1 & 3 & 5 \\
\hline
\end{tabular}

\subsection{Extração da Enzima do Sólido Fermentado}

A enzima foi extraída do material fermentado com $100 \mathrm{~mL}$ de solução aquosa de $\mathrm{NaCl} 2 \%$ $(\mathrm{m} / \mathrm{v})$. A mistura de sólido fermentado $(10 \mathrm{~g})$ e a solução extratora $(100 \mathrm{~mL})$ foram colocados em agitador orbital durante 1 hora, a 200rpm e $29^{\circ} \mathrm{C}$. A mistura foi filtrada em gaze e o sólido prensado manualmente para extração do líquido. O extrato resultante foi centrifugado por 30 minutos a $6.000 \mathrm{~g}$. O sobrenadante assim obtido foi utilizado para determinação da atividade enzimática.

\subsection{Determinação da Atividade Enzimática}

A atividade das enzimas produzidas foi determinada de acordo com a metodologia descrita por 
Silva (2007). Segundo o autor, a atividade lipásica pode ser quantificada pela hidrólise do paranitrofenolbutirato (pNPB) em 2-propanol a $25^{\circ} \mathrm{C}$ com adição de lipase. Para realizar a reação, um volume de $29 \mathrm{~mL}$ de tampão fosfato $100 \mathrm{mM}$ pH 8,0 é adicionado a $1,0 \mathrm{~mL}$ de solução de pNPB $15 \mathrm{mM}$ em 2-propanol em um reator encamisado, provido de agitação. A reação inicia-se com a adição da enzima. A variação da absorbância a um comprimento de onda de $410 \mathrm{~nm}$ foi monitorado por 9 minutos, retirando-se para isso cerca de $2 \mathrm{~mL}$ do sobrenadante a cada 1,5 minutos.

\section{Resultados e Discussão}

\subsection{Cinética de Crescimento do Penicillium sp.}

A cinética de crescimento do Penicillium sp. foi estudada a $28^{\circ} \mathrm{C}$, realizando-se contagem de esporos a cada $24 \mathrm{~h}$. Os resultados são apresentados na Figura 1:

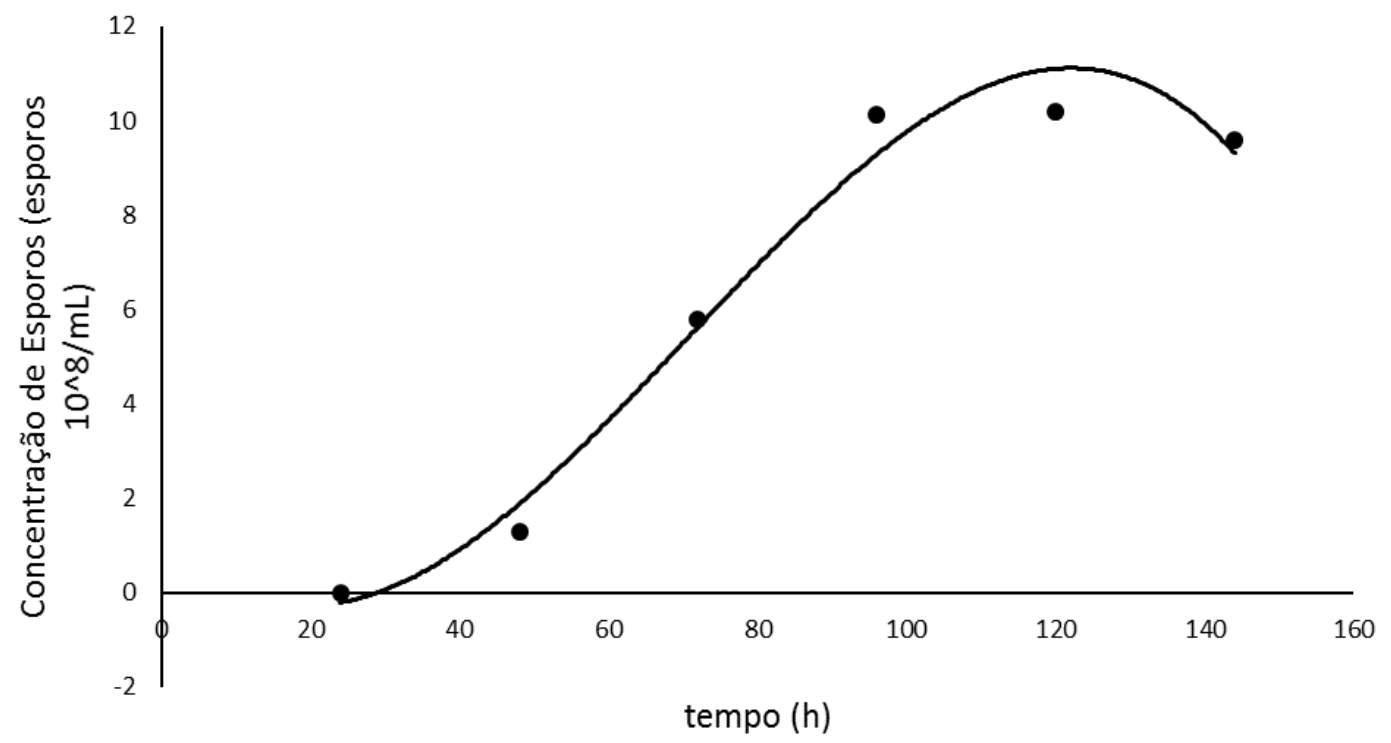

Figura 1: Resultados obtidos no estudo da cinética de crescimento do fungo Penicillium sp.

Pode-se observar que o fungo Penicillium sp. atingiu uma fase estacionária de crescimento entre o tempo de $96 \mathrm{~h}$ e $144 \mathrm{~h}$. Dessa forma foi selecionado o tempo de $120 \mathrm{~h}$ para a realização do inóculo com o fungo Penicillium sp.

\subsection{Cinética de Crescimento do B. megaterium}

Para a cinética de crescimento do $B$. megaterium foram retiradas amostras em intervalos de tempos e analisado a concentração celular por massa seca. Os resultados são apresentados na Figura 2. 


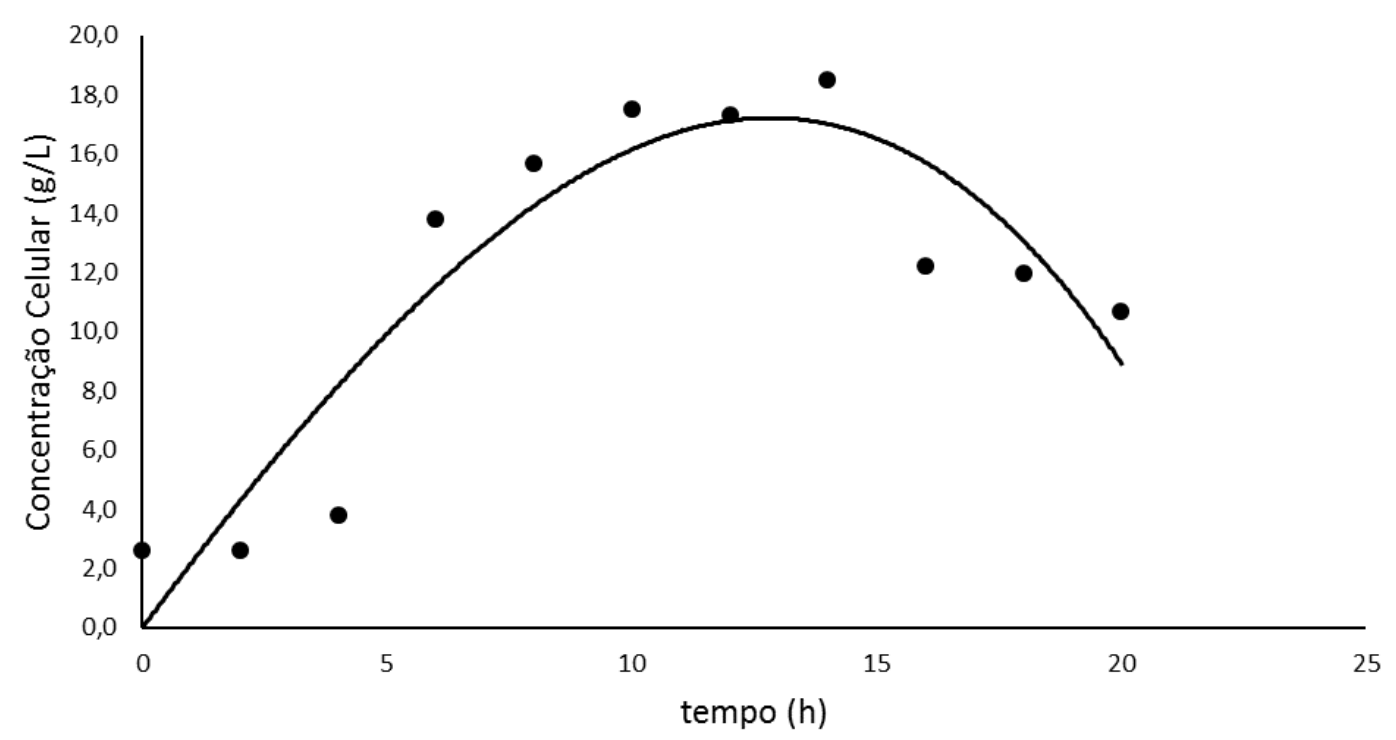

Figura 2. Resultados obtidos no estudo da cinética de crescimento da bactéria $B$. megaterium

O máximo de crescimento da bactéria B. megaterium ocorreu no intervalo entre 10 a 14 horas, com o pico em 14 horas, sendo, portanto, selecionado esse tempo para obtenção dos inóculos utilizados nas fermentações.

\subsection{Produção Enzimática}

Os resultados de produção enzimática a partir do fungo Penicillium $s p$. e da bactéria $B$. megaterium são apresentados na Tabela 2.

Pode-se observar que a produção de lipases foi baixa para ambos os microrganismos, embora o Penicillium $s p$. apresente uma produção um pouco maior (média de 0,3 UI/g substrato). Após análise estatística dos resultados verificamos que a umidade foi a única variável que interferiu na produção enzimática $(\mathrm{p}<0,05)$ quando utilizado o Penicillium $s p$, obtendo a equação 1 . Valores maiores de umidade conduziram a melhores produções.

$$
\mathrm{UI} / \mathrm{g}_{\text {susbstrato }}=0,078931+0,004500 \mathrm{U}
$$

Para as fermentações com o $B$. megaterium foi verificado que a Temperatura e a Umidade influenciaram nos resultados de produção de lipases, obtendo a equação 2.

$$
\mathrm{UI} / \mathrm{g}_{\text {substrato }}=-0,216885+0,009000 \mathrm{~T}+0,002667 \mathrm{U}
$$


Tabela 2: Resultados obtidos nas fermentações utilizando os microrganismos Penicillium sp. e

B. megaterium

\begin{tabular}{cccccc}
\hline & & $\begin{array}{c}\text { Teor de } \\
\text { umidade } \\
(\%)\end{array}$ & $\begin{array}{c}\text { Concentração } \\
\text { do indutor } \\
(\%)\end{array}$ & $\begin{array}{c}\text { Atividade Enzimática } \\
\left.\text { (UI/ } \mathrm{g}_{\text {substrato }}\right)\end{array}$ & $\begin{array}{c}\text { Atividade Enzimática } \\
\text { Penicillium sp. }\end{array}$ \\
\hline 1 & 28 & 40 & 1 & 0,36 & B. megaterium \\
2 & 28 & 50 & 1 & 0,28 & 0,16 \\
3 & 28 & 60 & 1 & 0,39 & 0,16 \\
4 & 28 & 40 & 3 & 0,26 & 0,21 \\
5 & 28 & 50 & 3 & 0,42 & 0,20 \\
6 & 28 & 60 & 3 & 0,38 & 0,16 \\
7 & 28 & 40 & 5 & 0,32 & 0,19 \\
8 & 28 & 50 & 5 & 0,28 & 0,16 \\
9 & 28 & 60 & 5 & 0,31 & 0,15 \\
10 & 33 & 40 & 1 & 0,38 & 0,20 \\
11 & 33 & 50 & 1 & 0,36 & 0,20 \\
12 & 33 & 60 & 1 & 0,33 & 0,20 \\
13 & 33 & 40 & 3 & 0,29 & 0,20 \\
14 & 33 & 50 & 3 & 0,33 & 0,20 \\
15 & 33 & 60 & 3 & 0,34 & 0,20 \\
16 & 33 & 40 & 5 & 0,25 & 0,20 \\
17 & 33 & 50 & 5 & 0,30 & 0,20 \\
18 & 33 & 60 & 5 & 0,34 & 0,20 \\
19 & 38 & 40 & 1 & 0,23 & 0,20 \\
20 & 38 & 50 & 1 & 0,28 & 0,20 \\
21 & 38 & 60 & 1 & 0,48 & 0,20 \\
22 & 38 & 40 & 3 & 0,20 & 0,20 \\
23 & 38 & 50 & 3 & 0,27 & 0,20 \\
24 & 38 & 60 & 3 & 0,43 & 0,20 \\
25 & 38 & 40 & 5 & 0,21 & 0,40 \\
26 & 38 & 50 & 5 & 0,20 & 0,20 \\
27 & 38 & 60 & 5 & 0,32 & 0,40 \\
28 & 33 & 50 & 3 & 0,13 & 0,40 \\
29 & 33 & 50 & 3 & 0,17 & 0,20 \\
\hline & & & & \\
\hline
\end{tabular}

\section{CONCLUSÃO}

Pode-se concluir que ambos os microrganismos produzem lipase por fermentação no estado sólido, embora ainda muito baixa. O teor de umidade foi uma variável que influenciou a produção de lipases quando utilizado o $B$. megaterium como o Penicillium $s p$, sendo, portanto, uma variável que requer estudos posteriores. 


\section{REFERÊNCIAS}

HASAN, F.; SHAH, A.A.; HAMEED, A. Industrial applications of microbial lipases. Enzyme Microbiol. Technol., v. 39, n. 1-2, p. 235-251, 2006.

KRIEGER, N.; BHATNAGAR, T.; BARATTI, J.C.; BARON, A.M.; LIMA, V.M.G.; MITCHELL, D. Non- Aqueous Biocatalysis in Heterogeneous Solvent Systems. Food Technol. Biotechnol., v. 42 (4), p. 279-286, 2004.

MENONCIN, S. Concentração, Imobilização e Caracterização Parcial de Lipase Produzida por Penicillium Verrucosum utilizando Fermentação em Estado Sólido. Dissertação de Mestrado, Departamento de Ciências Agrárias, URI, Erechim-RS, 2007.

MENONCIN, S., DOMINGUES, N.M., FREIRE, D.M.G., OLIVEIRA, J.V., LUCCIO, M., TREICHEL, H., OLIVEIRA, D. Imobilização de lipases produzidas por fermentação em estado sólido utilizando Penicillium verrucosum em suportes hidrofóbicos. Ciênc. Tecnol. Aliment., v. 29, n. 2, p. 440-443 - Campinas, 2009.

MESSIAS, J.A.; COSTA, B.Z.; LIMA, V.M.G.; GIESE, E.C.; DEKKER, R.F.H.; BARBOSA, A.M. Lipases Microbianas: Produção, propriedade e aplicações biotecnológicas. Semina: Ciênc. Exat. Tecnol. v. 32, n.2. p. 213-234, 2011.

OLIVEIRA, A.C.D, WATANABE, F.M.F., VARGAS, J.V.C., MARIANO, A.B., RODRIGUES, M.L.F. Comparação entre três bioprocessos para a produção de enzimas proteolíticas utilizando resíduos agroindustriais. Rev. Bras. Tecnol. Agroind., v. 06, n. 02, p. 822-831, 2012.

PASTORE, G.M., COSTA, V. dos S.R., KOBLITZ, M.G.B. Purificação parcial e caracterização bioquímica de lipase extracelular produzida por nova linhagem de Rhizopus sp. Ciênc. Tecnol. Aliment., Campinas, SP, 2003.

SILVA, D., MARTINS, E.S., SILVA, R. da, GOMES, E. Pectinase production by Penicillium viridicatum RFC3 by solid state fermentation using agricultural wastes and agro-industrial byproducts. Braz. J. Microbiol., v. 33, p. 318-324, 2002.

SILVA, J.A. Preparação de Biocatalisadores Utilizando Lipase de Cândida antractica Tipo B Imobilizada para Síntese de Ésteres de Vitamina A. Dissertação de Mestrado, Departamento de Engenharia Química, UFC, Ceará, 2007.

VARGAS, G.D.L.P. Estudo da produção de lipase por Penicillium simplicissimum utilizando torta de soja como substrato. Programa de Mestrado em Engenharia de Alimentos - Departamento de Ciências Agrárias - URI, Erechim, RS, 2004.

\section{AGRADECIMENTOS}

Os autores agradecem à UFES e à FAPES pelo auxílio financeiro para realização deste trabalho. 